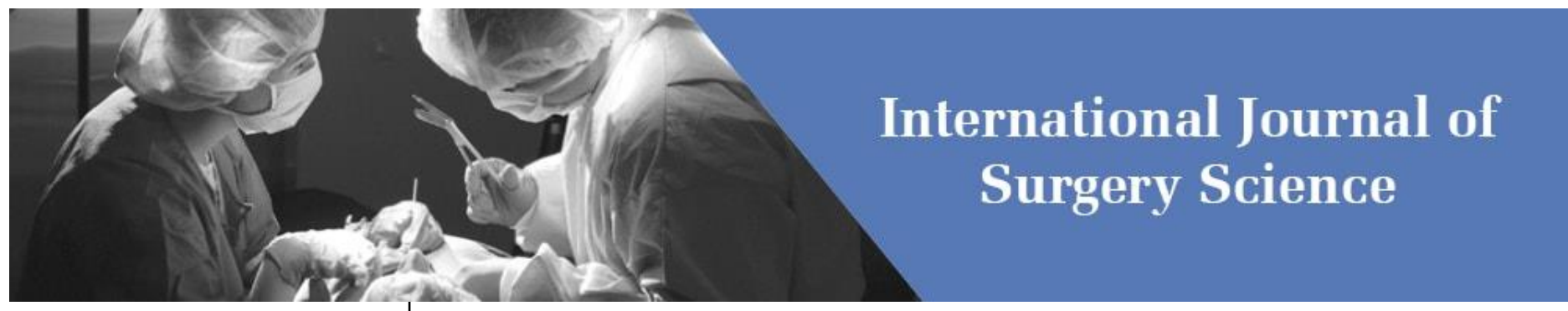

E-ISSN: 2616-3470

P-ISSN: 2616-3462

(C) Surgery Science

www.surgeryscience.com

$2019 ; 3(1): 201-206$

Received: 08-11-2018

Accepted: 12-12-2018

\section{Dr. Moloti}

MS, Senior Resident, Department of General Surgery Christian

Medical College and Hospital,

Ludhiana, Punjab, India

\section{Dr. Amit Mahajan}

MS, FMAS, FIAGES, FAIS

FIMSA, FVS Associate professor

Department of General Surgery

Christian Medical College and

Hospital, Ludhiana, Punjab, India

Dr. Anil Luther

MS, FMAS, FIAGES, FAIS,

FIMSA, Professor, Department of

General Surgery Christian Medical

College and Hospital, Ludhiana,

Punjab, India

\section{Correspondence}

Dr. Amit Mahajan

MS, FMAS, FIAGES, FAIS,

FIMSA, FVS Associate Professor

Department of General Surgery

Christian Medical College and

Hospital, Ludhiana, Punjab, India

\section{A prospective study on the factors affecting the outcome of Arterio-venous fistula in a tertiary care Centre of north India: Original research article}

\author{
Dr. Moloti, Dr. Amit Mahajan and Dr. Anil Luther
}

DOI: $\underline{\text { https://doi.org/10.33545/surgery.2019.v3.i1d.35 }}$

\section{Abstract}

Arterio-venous fistula is widely accepted as an optimal access method for hemodialysis as measured by lower morbidity and mortality figures and reduced maintenance costs. Arterio-venous fistula survives longer than grafts and catheters. The radio cephalic Arterio-venous fistula remains the method of choice for hemodialysis access. The Renal Association Vascular Access for Hemodialysis clinical practice guidelines have encouraged the earlier formation of AVFs in an attempt to reduce the number of End Stage Renal Disease patients commencing hemodialysis using a central venous catheter (CVC). Despite its advantages over grafts and catheters, early and late fistula failures are relatively common and represent an enormous burden on patients and healthcare system. This study aims to determine the various factors affecting the outcome of Arterio-venous fistula which are created in patients with end stage renal failure requiring vascular access.

Keywords: Arterio-venous fistula, Hemodialysis, Vascular access

\section{Introduction}

Arterio-venous fistula per definition describes an abnormal communication between an artery and a vein. Arterio-venous fistula (AVF) is generally accepted as an optimal access option for hemodialysis (HD), with the best long-term patency, low cost and low infection rates, when compared with grafts or central venous catheters ${ }^{[1]}$.

However, a significant percentage of AVF fails to mature adequately to support dialysis therapy and exhibit HD vascular access dysfunction (VAD). The vast majority of AVF dysfunction is either due to thrombosis and/or stenosis as a result of neointimal hyperplasia. Thus, neointimal hyperplasia which may cause early and late failure is the major mechanism for both thrombosis and stenosis ${ }^{[2]}$ Early failure, which is also called failure to mature, is defined as an AV fistula that never develops adequately for dialysis, or which fails within three months of starting hemodialysis ${ }^{[3]}$ All other fistula failures are categorized as late failures. It has recently been reported that between $20-50 \%$ of native AV fistulas failed to mature. ${ }^{4}$ In order to mature, a newly created fistula should obtain sufficient blood flow. Under resting conditions, mean blood flow in the radial artery is less than $25 \mathrm{~mL} / \mathrm{min}$.

However, for a successful fistula, mean blood flow in the artery must increase by at least 10-20 fold. The only way to achieve this increase is sufficient dilation of the artery. This artery prevalent access dysfunction causes significant morbidity and puts a heavy burden on the health care systems ${ }^{[5]}$. It remains challenging to accurately predict whether an individual Arteriovenous fistula (AVF) will mature and be usable for hemodialysis vascular access. Current best practice involves the use of routine clinical assessment and ultrasonography ${ }^{[6]}$.

This study was done to help the clinician to better understand the various factors that determine the outcome of AV fistula and thereby support the health care system to provide better, cost effective care in the society.

\section{Materials and Methods}

This was a prospective study conducted over a period of one and half years from $1^{\text {st }}$ Dec. 2015 to $30^{\text {th }}$ May 2017 in the department of General Surgery and department of Nephrology, Christian Medical College \& Hospital, 
Ludhiana. All patients presenting to Christian Medical College and Hospital, Ludhiana with end stage renal failure requiring a vascular access were observed for the various factors affecting the outcome of Arterio-venous fistula. Preoperatively, examination of the patient's vascular system in bilateral upper limb was done using Allen's test. Pre-operatively Ultra Sonography Doppler was done to assess the diameter and velocity of the vessels. Intraoperatively, the type of anastomosis was noted. Postoperatively, the timing of first cannulation,

complications and outcome of the AV fistula was noted. Patients were seen in the outpatient clinic within 2 weeks after their operative procedure and at 2 weekly intervals thereafter until their accesses were usable for dialysis.

The statistical test used was chi square test and t test. Data was collected and entered in excel spread sheet and analyzed with SPSS version 22 .

\section{Results and Analysis}

Table 1: Correlation of fistula outcome against time of referral after CKD (days)

\begin{tabular}{|c|c|c|c|}
\hline Time Of Referral After Ckd (Days) & Frequency & Success & Failure \\
\hline $20-30$ & $14(100 \%)$ & $11(78.54 \%)$ & $3(21.42 \%)$ \\
\hline $41-50$ & $2(100 \%)$ & $2(100 \%)$ & $0(0.00 \%)$ \\
\hline $51-60$ & $13(100 \%)$ & $10(76.9 \%)$ & $3(23.07 \%)$ \\
\hline $71-80$ & $5(100 \%)$ & $3(60.00 \%)$ & $2(40.00 \%)$ \\
\hline $81-90$ & $3(100 \%)$ & $2(66.66 \%)$ & $1(33.33 \%)$ \\
\hline $91-100$ & $2(100 \%)$ & $1(50.00 \%)$ & $1(50.00 \%)$ \\
\hline $120-130$ & $3(100 \%)$ & $0(0.00 \%)$ & $3(100 \%)$ \\
\hline $180-190$ & $1(100 \%)$ & $0(0.00 \%)$ & $1(100 \%)$ \\
\hline $360-370$ & $2(100 \%)$ & $1(50.00 \%)$ & $(50.00 \%)$ \\
\hline TOTAL & $45(100 \%)$ & $30(66.67 \%)$ & $15(33.33 \%)$ \\
\hline
\end{tabular}

Majority of the patients in the study were referred between 20-30 days and which also had more successful outcomes i.e. 11(78.54\%) (Table 1). However, on statistical analysis, the p value obtained was not significant.

Table 2: Correlation of fistula outcome against prior central vein cannulation

\begin{tabular}{|c|c|c|c|c|c|}
\hline \multirow{2}{*}{ Prior Central Vein Annulations (Y/N) } & \multicolumn{2}{|c|}{ Outcome } & \multirow{2}{*}{ Total } & \multirow{2}{*}{ P value } \\
\cline { 3 - 5 } & Failure & Success & & \\
\cline { 1 - 4 } & No & $100 \%$ & $0 \%$ & $1(100.00 \%)$ & \multirow{2}{*}{0.333} \\
\hline Yes & $31.82 \%$ & $68.18 \%$ & $44(100.00 \%)$ & \\
\hline
\end{tabular}

Out of the single patient who had no prior central vein cannulation the outcome was a failure as opposed to 44 patients who had prior central vein cannulation, who had a successful outcome of $68.18 \%$ and a failure of $31.28 \%$. (Table 2, Fig.2). However, on statistical analysis, the $\mathrm{p}$ value obtained was not significant.

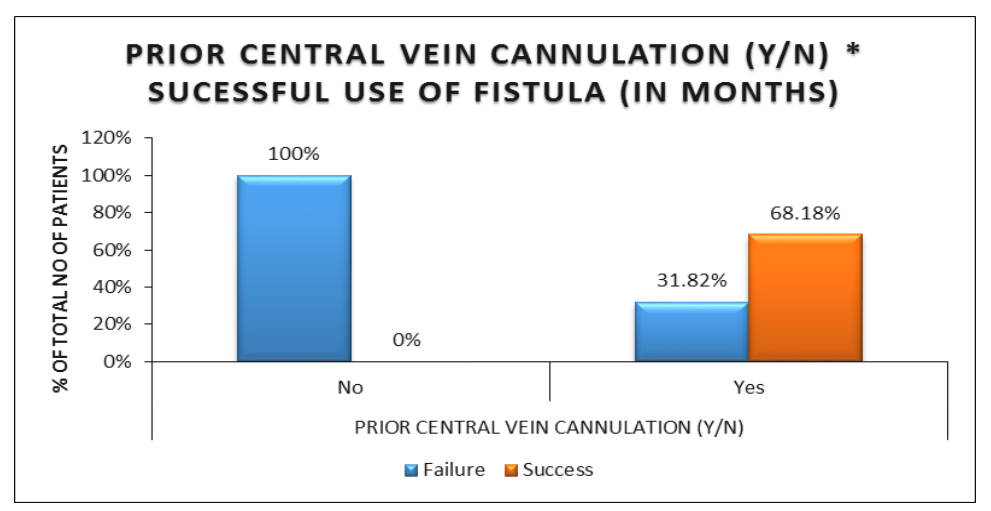

Fig 2: Prior central vein cannulation

Table 3: Correlation of fistula outcome against ultrasound vessel diameter (mm)

\begin{tabular}{|c|c|c|}
\hline Vessel & Failure & Success \\
\hline (R) Cephalic Vein At Elbow & 2.89 & 3.13 \\
\hline (L) Cephalic Vein At Elbow & 2.75 & 2.91 \\
\hline (R)Cephalic Vein At Wrist & 2.05 & 2 \\
\hline (L) Cephalic Vein At Wrist & 1.83 & 2.25 \\
\hline (R)Brachial Artery & 4.66 & 4.57 \\
\hline (L) Brachial Artery & 4.57 & 4.57 \\
\hline (R) Radial Artery & 2.18 & 2.27 \\
\hline (L) Radial Artery & 1.93 & 2.1 \\
\hline (R)Ulnar Artery & 2 & 2.02 \\
\hline (L) Ulnar Artery & 2.06 & 2.08 \\
\hline (R) Basilic Vein & 3.1 & 3.18 \\
\hline (L) Basilic Vein & 2.41 & 2.86 \\
\hline
\end{tabular}


The mean diameter of cephalic vein at right elbow $(3.13 \mathrm{~mm})$ is greater than left elbow $(2.91 \mathrm{~mm})$ and in the left wrist $(2.25 \mathrm{~mm})$ is greater than left wrist $(2 \mathrm{~mm})$ for successful outcome. The mean diameter of brachial artery is same in left and right side
$(4.57 \mathrm{~mm})$ and for radial artery right side $(2.27 \mathrm{~mm})$ shows greater diameter than left side $(2.1 \mathrm{~mm})$ for successful outcome. (Table 3, Fig. 3). However, on statistical analysis, the p value obtained was not significant.

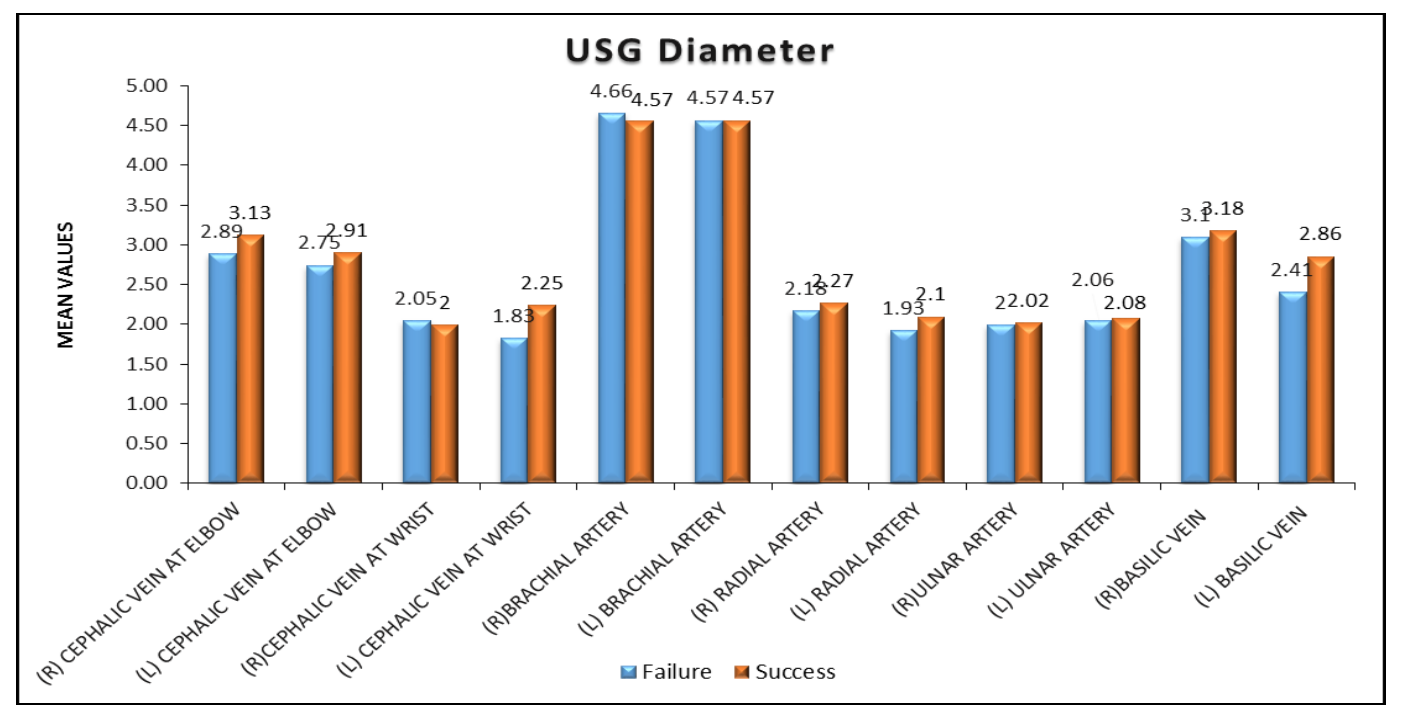

Fig 3: Mean values

Table 4: Correlation of fistula outcome against type and site of AV fistula

\begin{tabular}{|c|c|c|c|c|}
\hline $\begin{array}{c}\text { Type And Site of Av } \\
\text { Fistula }\end{array}$ & Failure & Success & $\begin{array}{c}\text { Total } \\
\text { Frequency }\end{array}$ & $\begin{array}{c}\text { P } \\
\text { Value }\end{array}$ \\
\hline Left Rc & $10(30.30 \%)$ & $13(69.70 \%)$ & 33 & 0.475 \\
\hline Right Rc & $1(33.33 \%)$ & $2(66.67 \%)$ & 3 & 1.000 \\
\hline Left Bc & $4(50 \%)$ & $4(50 \%)$ & 8 & 0.410 \\
\hline Right Bc & $0 \%$ & $100 \%$ & 1 & 1.000 \\
\hline Right And Left Bb & $0 \%$ & $0 \%$ & 0 & - \\
\hline
\end{tabular}

Majority of the type and site of AV fistula constructed was the left radiocephalic fistula (33 left RC Fistulas) with a successful outcome of $13(69.70 \%$ ) whereas the least was the right $\mathrm{BC}$ fistula which was done in a single patient and which had a successful outcome of $100 \%$. (Table 4). However, on statistical analysis, the $\mathrm{p}$ value obtained was not significant.

Table 5: Correlation of fistula outcome against intraoperative artery wall findings

\begin{tabular}{|c|c|c|c|c|}
\hline \multirow{2}{*}{$\begin{array}{c}\text { Intra Op } \\
\text { Arterial Wall }\end{array}$} & \multicolumn{2}{|c|}{ Outcome } & \multirow{2}{*}{ Total } & \multirow{2}{*}{$\begin{array}{c}\text { P } \\
\text { Value }\end{array}$} \\
\hline Normal & $20 \%$ & $80 \%$ & $35(100.00 \%)$ & \\
Atherosclerotic & $80 \%$ & $20 \%$ & $10(100.00 \%)$ & \multirow{2}{*}{0.001} \\
\hline Total & $15(33.33 \%)$ & $30(66.67 \%)$ & $45(100.00 \%)$ & \\
\hline
\end{tabular}

Intra-operatively, majority of the vessel which were reported as normal in the study had successful outcome with $80 \%$ and those arteries reported as atherosclerotic had $80 \%$ of outcomes as failure. (Table 5, Fig 5). On statistical analysis, the p value obtained was significant.

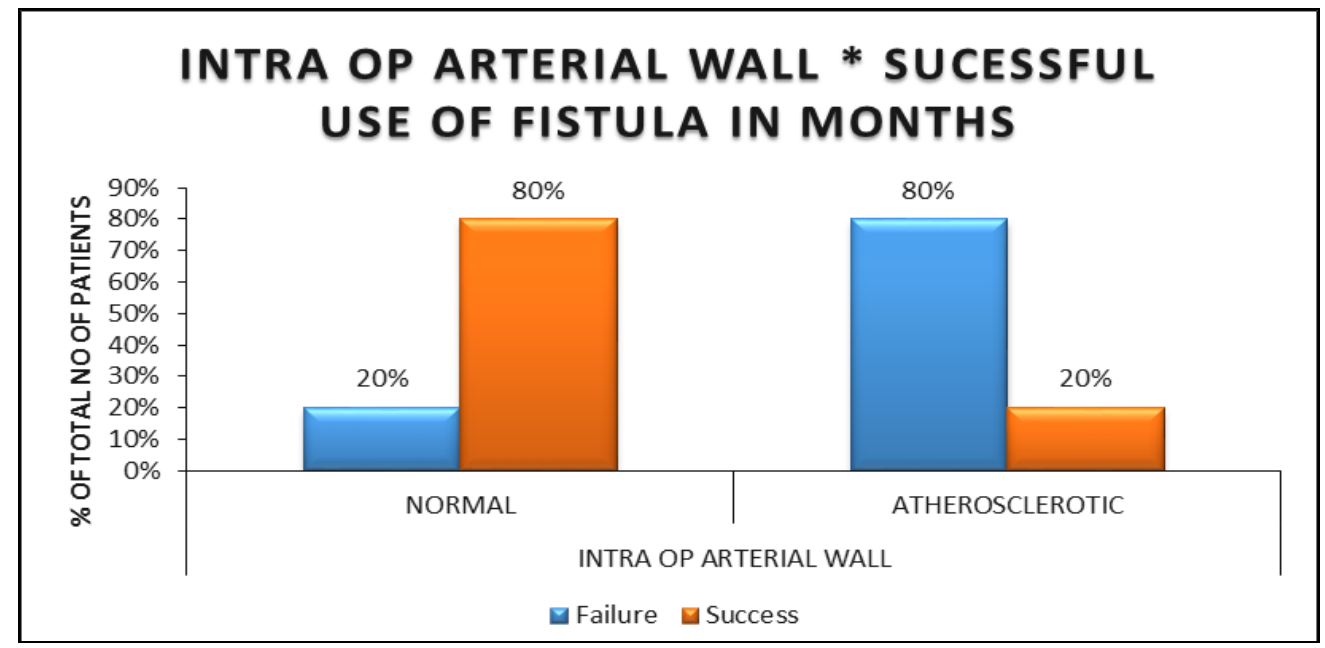

Fig 5: Outcome of fistula

Table 6: Correlation of fistula outcome against timing of first cannulation

\begin{tabular}{|c|c|c|c|}
\hline Timing Of Cannulation (Weeks) & Failure & Success & Total \\
\hline 4 & $5(38.45 \%)$ & $8(61.52 \%)$ & $13(100.00 \%)$ \\
\hline 6 & $9(29.97 \%)$ & $21(69.93 \%)$ & $30(100.00 \%)$ \\
\hline 8 & $1(50 \%)$ & $1(50 \%)$ & $2(100.00 \%)$ \\
\hline
\end{tabular}


Majority of the AV fistula was cannulated at $6^{\text {th }}$ week which had the highest successful outcomes with 21(69.93\%) as compared to when cannulated at $4^{\text {th }}$ week i.e. $8(61.52 \%)$ and $8^{\text {th }}$ week i.e. $(50 \%)$. (Table 6).

Table 7: Total outcome of AV fistula (after $6^{\text {th }}$ month follow up)

\begin{tabular}{|c|c|c|}
\hline Outcome & Frequency & Percentage \\
\hline Failure & 15 & $33.33 \%$ \\
\hline Success & 30 & $66.67 \%$ \\
\hline Total & 45 & $100.00 \%$ \\
\hline
\end{tabular}

Out of total $45 \mathrm{AV}$ Fistulas made, 15(33.33\%) patients and $30(66.67 \%)$ patients had failure and successful outcomes of the AV fistula respectively following 6 months of follow up. (Table 7, Fig. 7)

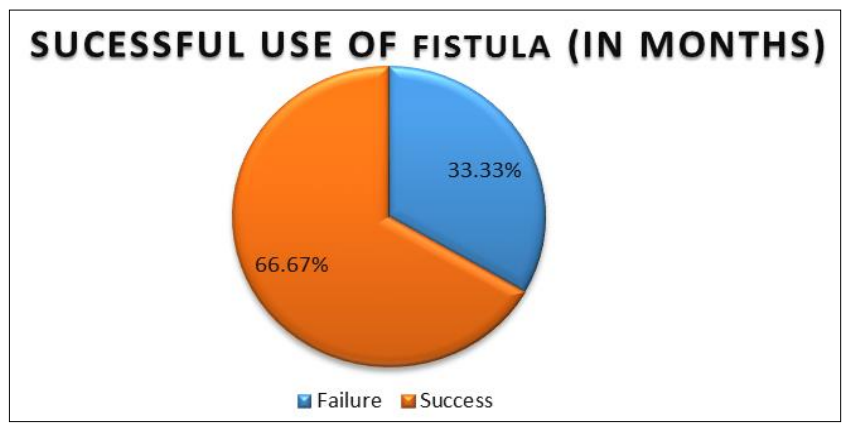

Fig 7: Outcome of AV fistula

Table 8: Outcome of fistula (in months)

\begin{tabular}{|c|c|c|}
\hline Outcome In Months & Frequency & Percentage \\
\hline 3 & $\begin{array}{c}7 \text { (secondary success) } \\
+30 \text { (Primary success) }\end{array}$ & $82.23 \%$ \\
\hline 6 & 30 (Primary success) & $66.67 \%$ \\
\hline No & 8 & $17.78 \%$ \\
\hline
\end{tabular}

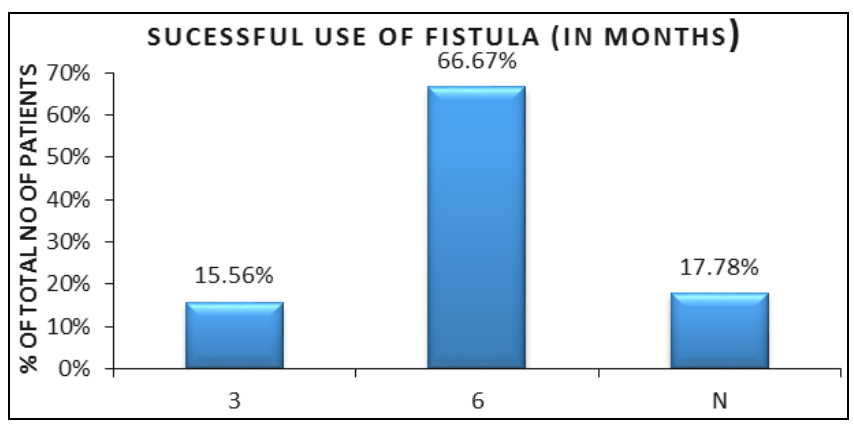

Fig 8: Outcome of AV Fistula

Out of total 45 AV Fistulas made, there was a Primary success of $30(66.67 \%)$ and a secondary success of $7(15.56 \%)$ by $3^{\text {rd }}$ month. However, at the end of the 6 months of follow up, none of the secondary success AV fistulas were functional. (Table 8, Fig. 8)

\section{Discussion}

A total of 45 arterio-venous fistulas were made during the study period all by experienced surgeons in the General Surgery vascular unit which also included 6 months follow up of each patient. All fistulas were made by end to side anastomosis with 5 'o' or 6 'o' prolene sutures.

\subsection{Time of Referral after CKD}

Majority of the patients in our study were referred between 2030 days and which also had more successful outcomes i.e.
11(78.54\%). The patient group in the study who were referred between 120-130 days and 180-190 days had highest failure outcomes with $100 \%$. In a study by Lin CL et al. 78 patients who were on hemodialysis with $37(47.1 \%)$ qualified for the early referral group (<6months) and 41(52.6\%) were designated to the late referral group ( $>6$ months). Patients with early referral had significant survival rate as compared to the late referral group of patients ${ }^{[7]}$.

\subsection{Prior Central Vein Cannulation}

Out of the total 45 patients, 38 patients who had no prior access procedures done had more successful outcomes with $71.05 \%$ than patients who had prior access procedure with $42.86 \%$. Out of the single e patient who had no prior central vein cannulation the outcome was a failure as opposed to 44 patients who had prior central vein cannulation, who had a successful outcome of $68.18 \%$ and a failure of $31.28 \%$. However, on statistical analysis, the $\mathrm{p}$ value obtained was not significant.

In a study by Al-Salman $\mathrm{M}$ et al. 36 patients with end-stage renal disease (ESRD) who had previous history of subclavian vein catheterization with venography demonstrated greater than $50 \%$ central vein lesions in 13 of the 38 extremities yielding a prevalence of $34 \%$ and increase in AV fistula created ${ }^{[8]}$.

\subsection{Pre-Operative Ultrasound Diameter}

Out of the total ultrasonography measured diameter of vessels, maximum mean diameter was of right brachial artery with a value of $4.6 \mathrm{~mm}$ and minimum of right ulnar artery with a value of $2.01 \mathrm{~mm}$. Maximum mean diameter of vein was of basilica vein with a value of $3.15 \mathrm{~mm}$ and minimum value was found in right cephalic vein at wrist with $2.02 \mathrm{~mm}$ diameter. The mean diameter of cephalic vein at right elbow $(3.13 \mathrm{~mm})$ is greater than left elbow $(2.91 \mathrm{~mm})$ and in the left wrist $(2.25 \mathrm{~mm})$ is greater than left wrist $(2 \mathrm{~mm})$ for successful outcome. The mean diameter of brachial artery is same in left and right side $(4.57 \mathrm{~mm})$ and for radial artery right side $(2.27 \mathrm{~mm})$ shows greater diameter than left side $(2.1 \mathrm{~mm})$ for successful outcome. However, on statistical analysis, the $\mathrm{p}$ value obtained was not significant.

In a study by Parmar J et al. 21 patients with end stage renal failure were classified into two groups as follows. Group-1: Patients with radial artery internal diameter $<1.5 \mathrm{~mm}(11$ patients) Group-2: Patients with radial artery internal diameter > $1.5 \mathrm{~mm}$ (10 patients). In Group-1, 5/11 (45.5\%) of the radial artery AVFs had failed within 12 weeks of construction. In contrast, in Group-2 patients all of the AVFs were patent at 12 weeks ${ }^{[9]}$.

Present guidelines suggest a minimum diameter of the artery at 2 $\mathrm{mm}$ for successful AVF creation at the wrist, but agreement on minimal arterial diameters for other sites is lacking to date. Current guidelines suggest minimum venous diameter of $2 \mathrm{~mm}$ for a cephalic AVF at the wrist, and no agreed minimum measures exist for other sites to date. These measures have been evidenced by meta-analysis demonstrating significant differences in fistula success rates between cephalic vein diameter $2.0(71 \%)$ and $2.0 \mathrm{~mm}(29 \%){ }^{[5]}$ Radial arteries with a diameter of $<1.5 \mathrm{~mm}$ had an almost $50 \%$ risk of immediate fistula dysfunction as compared with larger radial artery ${ }^{[9]}$

For this study we used only a single technique for making all the fistulas i.e. end to side anastomosis, where end of the vein was anastomosed to the side of the artery and there was a successful outcome of the fistula with $66.67 \%$ as compared to failure in outcome with $33.33 \%$.

In a study by Galic G et al. conducted in 2008 in university 
hospital, Mostar, the advantages of end to side arterio-venous anastomosis was compared over the other two types of arteriovenous fistula in dialysis patients. Within a 6-month interval following the establishment of vascular access, the first complications arose in $62.50 \%$ of patients with end to end AV anastomosis, $10.76 \%$ in those with end to side AV anastomosis and $18.88 \%$ in those with side to side AV anastomosis. 24 months subsequent to the establishment of vascular access, the AV fistula was still functional in $52.50 \%$ of the patients with end to end AV anastomosis, $89.23 \%$ in those with end to side $\mathrm{AV}$ anastomosis and $81.11 \%$ in those with side to side AV anastomosis ${ }^{[10]}$.

\subsection{Type and Site of Anastomosis}

Majority of the type and site of AV fistula constructed was the left radiocephalic fistula (33 left RC Fistulas) with a successful outcome of $13(69.70 \%), 3(6.67 \%)$ patients underwent right radiocephalic (RC) AV fistula surgery out of which $66.67 \%$ of the outcome was successful and $33.33 \%$ was a failure, 8 Patients (17.78\%) underwent left brachiocephalic (BC) AV fistula surgery out of which $50 \%$ of the outcomes were failures. The least was the right $\mathrm{BC}$ fistula which was done in a single patient and which had a successful outcome of $100 \%$. However, on statistical analysis, the $\mathrm{p}$ value obtained was not significant.

In a study by Glass C et al. 204 RC, 1 brachiobasilic, and 9 brachiocephalic $(\mathrm{BC})$ primary fistulas were created. Immediate failure rates for $\mathrm{RC}$ fistulas were lower than for $\mathrm{BC}$ fistulas but not significantly so $(12 \%$ vs $22 \%)$. One-year primary and secondary patency for RC fistulas was $54 \%$ and $66 \%$ respectively. The secondary patency rate at 1 year for $\mathrm{RC}$ fistulas using cephalic vein of diameter $<2.5 \mathrm{~mm}$ was lower than for fistulas created with cephalic vein $>2.5 \mathrm{~mm}(49 \%$ vs $72 \%$; log-rank test, $\mathrm{P}=.005)^{[5]}$.

\subsection{Complications and Treatment}

Out of the total 15 unsuccessful AV fistulas, thrombosis was the major complication present i.e. in $10(22.22 \%)$ fistulas. Least complications were by wound infection i.e. $1(2.22 \%)$ fistula and by vessel blowout i.e. 1 (2.22\%) fistula out of which the vessel blowout was a result of trauma the patient had sustained.

Out of the 10 fistulas complicated by thrombosis, 6 fistulas were treated with surgical thrombectomy out of which 4 of the fistulas were used till $3^{\text {rd }}$ month and 2 fistulas were not usable even with the intervention, for another 4 of the thrombosed AV fistulas fogarty catheter was used where 3 fistulas were not usable even with intervention and 1 fistula was successful till $3^{\text {rd }}$ month. For the stenosis dilatation was attempted out of which none of the fistulas were usable. The fistula which was infected, local application of antibiotic cream with dressing and oral antibiotic was given but the fistula could not be used. One of the patients presented to the casualty with history of trauma to the fistula site which resulted in the blow out of the fistula for which patient was taken to the operation theatre where the AV fistula was ligated and patient was dialysed using central venous line.

In a study by Qing Y et al. conducted in Shanghai first people's hospital affiliated to Jiaotong university reported that the most frequent complication seen following creation of an AV fistula was thrombosis $(13.86 \%)^{[11]}$.

\subsection{Outcome of Fistula}

$30(66.67 \%)$ patinets in our study had primary success and 15 $(33.33 \%)$ patinets had secondary success following $3^{\text {rd }}$ month of follow up and by the end of the $6^{\text {th }}$ month of follow up only $66.67 \%$ patients had functional $\mathrm{AV}$ fistulas. In a study by
Beathard et al. 68 fistulae were created and followed postoperatively which showed $24(35 \%)$ of 68 fistulae failed to develop adequately to support dialysis whereas the remaining 44 $(65 \%)$ fistulae had a successful outcome. All were identified by physical examination within 8 weeks of access creation ${ }^{[12]}$ The percentage of successful outcomes of AV fistulas in our study was comparable to the study by Beathard et al.

\section{Conclusion}

This study has demonstrated that various factors can determine the successful outcome and the failure of an arterio-venous fistula which includes age, sex, timing of referral for AV fistula creation, duration of illness, use of anti-platelets, prior access procedures, central vein cannulation, physical examination (edema of hand, previous surgical scar, hand and nail bed changes, ischemia of hand, Allen's test), use of preoperative ultrasound to measure diameter of the vessels and the flow velocity in blood vessel, intra-operative findings of vessel, histopathological examination of the arterial wall, type of anastomosis, site of anastomosis, time of cannulation and the various complications and treatment done for those complications.

This study has also demonstrated the need for careful planning by a vascular surgeon and selection of patients in consultation with the nephrologist for the creation of Arterio-venous fistula so that there will be an increase in the successful outcomes of a created AV access, thereby increasing the use of AV fistulas as the first means of access for the purpose of hemodialysis in an end stage renal disease and the need for a dedicated renal access clinic where all planning for the creation of AV fistula can be done with the use of pre-operative doppler scan and also where difficult access can be assessed pre-operatively. This study also encourages the use of endovascular procedures to improve the salvaging and thus improving secondary success of AV fistula.

\section{Reference}

1. Brescia MJ, Cimino JE, Appel K, Hurwich BJ. Chronic hemodialysis using venipuncture and a surgically created arteriovenous fistula. N Engl. J Med. 1966; 275:1089-92.

2. Allon M, Ornt DB, Schwab SJ, Rasmussen C, Delmez JA, Greene $\mathrm{T}$ et al. Factors associated with the prevalence of arteriovenous fistulas in hemodialysis patients in the HEMO study. Kidney Int. 2000; 58:2178-85.

3. Sedlacek M, Teodorescu V, Falk A, Vassalotti JA, Uribarri J. Hemodialysis access placement with preoperative noninvasive vascular mapping: comparison between patients with and without diabetes. Am J Kidney Dis. 2001; 38:560-4.

4. Konner K, Hulbert-Shearon TE, Roys EC, Port FK. Tailoring the initial vascular access for dialysis patients. Kidney Int. 2002; 62:329-38.

5. Glass C, Johansson M, DiGragio W, Illig KA. A metaanalysis of preoperative duplex ultrasound vessel diameters for successful radio cephalic fistula placement. J Vasc Surg. 2009; 33:65-9.

6. Ku YM, Kim YO, Kim JI, Choi YJ, Yoon SA, Kim YS et al. ultrasonographic measurement of intima-media thickness of radial artery in pre-dialysis uraemic patients; comparision with histological examination. Nephrol Dial. 2006; 21:71520.

7. Lin CL, Chuang FR, Wu CF, Yang CT. Early referral as an independent predictor of clinical outcome in end stage renal disease on hemodialysis and continuous ambulatory peritoneal dialysis. Ren Fail. 2004; 26:531-7. 
8. Al-Salman M, Rabee M, Abu-Aisha H, Trengganu H, Aldamegh N, aleh Al-Smeyer S et al. Central vein stenosis in patients with prior subclavian vein catheterization for maintenance dialysis. Saudi journal of kidney diseases and transplantation. 2017; 8:119-22.

9. Parmar J, Aslam M, Standfield N. Pre-operative radial arterial diameter predicts early failure of Arterio-venous fistula for haemodialysis. Eur. J Vasc. Endovasc Surg. 2007; 33:113-5.

10. Galic G, Kvesic A, Tomic M, Rebac Z, Brekalo Z, Martinovic $\mathrm{V}$ et al. The advantages of end to side arteriovenous anastomosis over the other two types of anastomosis in dialysis patients. Coll Antropol. 2008; 32:109-14.

11. Qing Y, Hua Y, Huang J, Sheng C, Lijun W, Weijie Y. Distribution and complications of native Arterio-venous fistulas in maintenance hemodialysis patients: a singlecentre study. J nephrol. 2011; 24:597-603.

12. Beathard GA, Arnold P, Jackson J, Litchfield T. Physician operator's forum of RMS lifeline. Aggressive treatment of early fistula failure. Kidney Int. 2003; 64:1487-94. 